\title{
Clinical evaluation of DMARDs and NSAIDs in cases of Rheumatoid arthritis in Chhattisgarh
}

\author{
Basant Kumar Maheshwari', Prafulla Kumar Khodiar², Debapriya Rath ${ }^{3}$ \\ ${ }^{1}$ Associate Professor, Department of Pharmacology, Pt JNM Medical College, Raipur, ${ }^{2}$ Associate Professor, ${ }^{3}$ Assistant \\ Professor, Department of Biochemistry, Pt JNM Medical College, Raipur
}

Background: Rheumatoid arthritis (RA) is an autoimmune disease characterized by polyarticular inflammation with systemic symptoms like malaise, fatigue and fever. Various groups of drugs have been used along with supportive therapies (physical and occupational) for the treatment of rheumatoid arthritis. Non-steroidal anti-inflammatory drugs (NSAIDs) and disease modifying agents in rheumatoid disease (DMARDs) are the two major classes among them. However, none of these medications have proved to be successful enough to be accepted universally as the standard therapy for RA. Aims and Objective: To compare the clinical efficacy of nimesulide as a standalone therapy with combination therapy of nimesulide plus methotrexate and nimesulide plus hydroxychloroquine. Materials and Methods: The study comprised of three groups of rheumatoid arthritis patients. Each group consisted of 32 study subjects. Group 1, 2 and 3 consisted of patients taking nimesulide alone, nimesulide plus hydroxycholoroquine and nimesulide plus methotrexate respectively for the disease. The cases were followed up to a period of six months and based upon subjective \& objective (Radiological and serological examination) criteria, results have been evaluated. Results: Observations have revealed that nimesulide plus hydroxycholoroquine combination produced significant improvement in the patients in mild, moderate and severe cases of rheumatoid arthritis as compared to nimesulide plus methotrexate. The improvement observed was least in the patients who received nimesulide as standalone therapy. No significant adverse drug reaction was seen in any of the study groups. Conclusion: The study concludes that nimesulide plus hydroxychloroquine combination can be used in cases of rheumatoid arthritis as disease modifying drugs without noticeable toxicity in doses used in this study in patients who have no renal and hepatic insufficiency.

Key words: Rheumatoid arthritis, NSAIDS, DMARDS, Methotrexate, Hydroxychloroquine
Access this article online Website:

http://nepjol.info/index.php/AJMS DOI: 10.3126/ajms.v9i1.18702 E-ISSN: 2091-0576 P-ISSN: $2467-9100$

\section{INTRODUCTION}

Rheumatoid arthritis (RA) is an autoimmune disease characterized by poly-articular inflammation with systemic symptoms like malaise, fatigue and fever. In its natural course it is a chronic progressive and gradually crippling disorder. ${ }^{1}$ The etiology of the disorder is not fully understood, but, various studies point towards a genetic predisposition like association with HLA class II antigen DR4. ${ }^{2}$ The pathogenesis of the disease is believed to be mediated by activated $\mathrm{T}$ lymphocytes which infiltrate into the synovia. These activated $\mathrm{T}$ cells further activate the synovial macrophages, chondroblasts and fibroblasts leading to the secretion of various pro-inflammatory mediators like interleukin-1, TNF $\alpha$ and lysosomal enzymes which ultimately prove to be the chondrolytic and osteolytic agents. ${ }^{3}$ The activation of the T cells is caused by auto reactive $\mathrm{B}$ cells which produce auto antibodies like Rheumatoid factor which causes immune complex formation and destruction of joints. As disease evolves autonomous non $\mathrm{T}$ cell dependent pathways emerge which appears to dominate the later stages of disease. ${ }^{4}$

Various groups of drugs have been used along with supportive therapies (physical and occupational) for the treatment of rheumatoid arthritis. Non-steroidal 
anti-inflammatory drugs (NSAIDs) and disease modifying agents in rheumatoid disease (DMARDs) are the two major classes among them. ${ }^{5,6}$ They are used as standalone or in combination therapy. However, none of these medications have proved to be successful enough to be accepted universally as the standard therapy for RA.

The present study was undertaken to evaluate the clinical efficacy of nimesulide (a NSAID) as standalone therapy and in combination with two DMARDs (hydroxychloroquine and methotrexate).

\section{Aim of the study}

To compare the clinical efficacy of nimesulide as a standalone therapy with combination therapy of nimesulide plus methotrexate and nimesulide plus hydroxychloroquine.

\section{MATERIALS AND METHODS}

The study was conducted in the department of Pharmacology, Pt JNM Medical College, Raipur in association with department of Orthopaedics, Dr. BRAM Hospital, Raipur. Informed and written consent was obtained from all the study participants. The study was approved by the institutional ethical committee.

The study comprised of three groups of rheumatoid arthritis patients. Each group consists of 32 study subjects. Group 1, 2 and 3 consisted of patients taking nimesulide alone, nimesulide and hydroxycholoroquine \& nimesulide and methotrexate respectively as the therapy for the disease.

\section{Inclusion criteria}

Patients of age group 18 to 75 years were included in the study who fulfilled the criteria of American Rheumatic committee guidelines. Patients with disease lasting for more than six months and active disease with at least three out of the following parameters were included in the study. 1 - erythrocyte sedimentation rate $>28 \mathrm{~mm} /$ hour, 2- morning stiffness lasting 45 minute or more, 3- eight or more tender joints, 4 - three or more swollen joints.

Only patients who were well oriented, co-operative and willing to comply with the terms at this protocol were included in the study along with the above criteria.

\section{Exclusion criteria}

Patients who had RA functional class IV or having a history of other inflammatory joint diseases like mixed connective tissue disease, seronegative spondyloarthropathy, arthropathic-psoriasis, reiter syndrome, systemic lupus erythromatosis (SLE), sarcoidosis, history of any arthritis with onset prior to 16 year of age congenital or acquired severe immunodeficiency, history of cancer or lympho- proliferative disease or any patient who has received total lymphoid irradiation were excluded from the study.

All the drugs were administered by oral route in the form of tablets. The dosage of nimesulide, hydroxycholoroquine and methotrexate was $100 \mathrm{mg} \mathrm{BD}, 75 \mathrm{mg}$ OD and $2.5 \mathrm{mg}$ $\mathrm{BD}$ twice weekly respectively. The patients were followed for duration of 6 months and then evaluated.

The response to treatment was evaluated as serological, hematological and radiological tests. Also the incidence of adverse drug reactions was recorded during the period of follow up.

Statistical analysis was done with Microsoft excel 2016.

\section{RESULTS}

The study included 32 patients (Table 1) of each group. All the study subjects were evaluated before and after 6 months of therapy. Clinical and hematological improvement was observed in the patients from all the study groups.

Among the 96 study subjects 90 patients were having a high ASO titre before the beginning of the therapy among which $36(40 \%)$ patients became seronegative for ASO titre. The change of serum ASO levels was maximum in the group receiving nimesulide and hydroxycholoroquine and was also statistically significant. The group receiving only nimesulide showed the maximum improvement in CRP levels but the results were not statistically significant. None of the study participants showed any major change in the rheumatoid factor levels. The improvement in ESR values was highest in the third group of patients receiving nimesulide and methotrexate in comparison to the second group with nimesulide plus hydroxychloroquine but the change was not significant statistically. The mean ESR in the first group with nimesulide standalone therapy after 6 months of therapy was found to be increased to our surprise (Table 2).

Similar to the serological findings there was a significant and gross improvement in the number of involved joints in all the three study groups. The number of joints involved was decreased by $40 \%$. The two groups receiving the combination therapy showed a very high and statistically significant improvement in comparison to the first group with nimesulide therapy only. The improvement was highest with nimesulide and hydroxychloroquine but the difference from the third group was not statistically significant. The number of swollen and tender joints also showed a maximum improvement in the second group and this was statistically significant in comparison to the other two groups. Improvement in joint space reduction (radiologically) was also seen all the groups (Table 3). 
Table 1: Age and Sex distribution of the study groups

\begin{tabular}{lcccc} 
& Nimesulide $(\mathbf{N}=\mathbf{3 2})$ & Nimesulide+Hydroxyhloroquine $(\mathbf{n}=\mathbf{3 2})$ & Nimesulide+Methotrexate $(\mathbf{n}=\mathbf{3 2})$ & $\mathbf{p}$ value \\
\hline Age & & & & \\
Mean \pm S.D & $32.7 \pm 18.2$ years & $35.6 \pm 10.4$ years & $28.8 \pm 9.6$ years & $>0.05$ \\
Male:female & $10: 22$ & $12: 20$ & $9: 23$ & $>0.05$ \\
\hline
\end{tabular}

\begin{tabular}{|c|c|c|c|c|c|c|c|c|c|c|}
\hline \multicolumn{11}{|c|}{ Hematological and serological findings } \\
\hline & \multicolumn{3}{|c|}{ Nimesulide } & \multicolumn{3}{|c|}{$\begin{array}{c}\text { Nimesulide + } \\
\text { hydroxyhloroquine }\end{array}$} & \multicolumn{3}{|c|}{ Nimesulide + methotrexate } & \multirow[t]{2}{*}{$\begin{array}{l}\text { p value } \\
\text { (Annova) }\end{array}$} \\
\hline & Before & After & Change & Before & After & Change & Before & After & Change & \\
\hline $\begin{array}{l}\text { Number of } \\
\text { patients with high } \\
\text { ASO titre }\end{array}$ & 29 & 19 & $34.5 \%$ & 23 & 14 & $39.1 \%$ & 28 & 21 & $25 \%$ & $<0.01$ \\
\hline $\begin{array}{l}\text { Number of } \\
\text { patients with high } \\
\text { CRP }\end{array}$ & 16 & 8 & $50.0 \%$ & 18 & 10 & $44.4 \%$ & 24 & 19 & $20.8 \%$ & $<0.01$ \\
\hline $\begin{array}{l}\text { Number of } \\
\text { patients with } \\
\text { positive RA factor }\end{array}$ & 5 & 5 & 0 & 5 & 5 & 0 & 8 & 8 & 0 & $>0.05$ \\
\hline $\begin{array}{l}\text { ESR } \\
(\text { mean } \pm S . D)\end{array}$ & $39.66 \pm 21$ & $43.5 \pm 19$ & $3.84 \pm 2.1$ & $32.1 \pm 21$ & $24.8 \pm 57$ & $0.3 \pm 5.6$ & $48.63 \pm 3$ & $10.554 \pm 5.7$ & $10.554 \pm 5.7$ & $<0.01$ \\
\hline
\end{tabular}

\begin{tabular}{|c|c|c|c|c|c|c|c|c|c|c|}
\hline \multicolumn{11}{|c|}{ Clinical changes in joint involvement } \\
\hline & \multicolumn{3}{|c|}{ Nimesulide } & \multicolumn{3}{|c|}{ Nimesulide+hydroxychloroquine } & \multicolumn{3}{|c|}{ Nimesulide+methotrexate } & \multirow{2}{*}{$\begin{array}{l}\text { p value } \\
\text { (Annova) }\end{array}$} \\
\hline & Before & After & Change & Before & After & change & Before & After & Change & \\
\hline $\begin{array}{l}\text { Total number of } \\
\text { joints involved }\end{array}$ & 86 & 67 & $22.1 \% \#$ & 124 & 62 & $50 \%$ & 120 & 68 & $43.3 \%$ & $<0.001$ \\
\hline Swollen joint count & 66 & 31 & $53.0 \%$ & 90 & 25 & $72.2 \%{ }^{*}$ & 96 & 43.4 & $54.8 \%$ & $<0.01$ \\
\hline Tender joint count & 70 & 46 & $34.3 \%$ & 69 & 18 & $73.9 \% *$ & 93 & 38 & $59.1 \%$ & $<0.001$ \\
\hline $\begin{array}{l}\text { Reduced joint } \\
\text { space by radiology }\end{array}$ & 5 & 4 & $20.0 \%$ & 6 & 4 & $33.3 \%$ & 8 & 5 & 37.55 & $>0.05$ \\
\hline
\end{tabular}

\section{DISCUSSION}

With the disease modifying therapy currently available, complete remissions of rheumatoid arthritic are disappointingly rare. Therefore, most clinicians have resorted to using combinations of drugs to treat a substantial subgroup of patients. The recent trend in the treatment of RA is the use of disease modifying drugs either alone or in combination with NSAIDS especially with nonspecific cox-inhibitor, however most of the drugs used alone have poor and disappointing results.

We sort to design and conduct this study that would reflect clinical practice and yield results applicable to patients with rheumatoid arthritis and their physicians.

In the present study a total number of 96 patients were followed up for a period of six months. Observation have revealed that nimesulide and hydroxychloroquine combination produced significant improvement in the patient with in all mild, moderate \& severe cases of rheumatoid arthritis as compared nimesulide plus methotrexate. The improvement observed was least in the patients who received nimesulide as standalone therapy.

The best thing about the study was that, no significant adverse effect was observed throughout the study. No patient had withdrawn from the study due to the adverse reaction in any of the group of the patients.

Hemologlobin level and Total WBC count was not affected throughout the study. Rather there was increase in $\mathrm{HB} \%$ in mild cases of patients who were treated with nimesulide plus chloroquine combination, which indicate that the drugs did not produce haematological disorder in the doses used. 
Normally NSAIDS do not alter the C.R.P. level in patients of RA but in this study it was observed that nimesulide altered the C.R.P. level in 8 patients out of 16 who were positive for C.R.P. and remaining 8 patients also showed significant decrease in titer. Another interesting finding was 80 patients were positive for A.S.O. titer and 54 became negative after treatment and rest were mild positive. This finding is quite significant.

Nimesulide and methotrexate combination has significantly altered the E.S.R. value in cases of mild, moderate \& severe cases of patients after the treatment which indicates that this combination therapy has altered the disease process and could be because methotrexatehas immunesuppressant action and thus more anti-inflammatory effect.

\section{CONCLUSION}

The study concludes that hydroxychloroquine or methotrexate, along with nimesulide combination can be used in cases of rhreumatoid arthritis as disease modifying drug without causing noticeable toxicity in doses used in this study in patients who have no renal \& hepatic insufficiency.

It is concluded that nimesulide and hydroxychloroquine combination has given satisfactory result in the low dose schedule of hydroxychloroquine plus nimesulide. However the long term use of the drugs has to be evaluated. Further verification is required of the finding for efficacy the drug combination used in this study by taking control groups of hydroxychlroquine and methotrexate alone against their combination with nimesulide which would give a better appreciation of the drug efficacy.

\section{ACKNOWLEDGEMENT}

1. Department of Orthopaedics, Dr BRAM Hospital, Raipur (CG)

\section{REFERENCES}

1. Kahlenberg JM and Fox DA. Advances in the Medical Treatment of Rheumatoid Arthritis. Hand clinics 2011;27(1):11-20.

2. Jefferies WM. The etiology of rheumatoid arthritis. Med Hypotheses 1998; 51(2):111-114.

3. Mclnnes IB and Schett $G$. The pathogenesis of rheumatoid arthritis. N Engl J Med 2011; 365(23):2205-2219.

4. Anić B and Mayer M. Pathogenesis of rheumatoid arthritis. Reumatizam 2014; 61(2):19-23.

5. Cash JM and Klippel JH. Second line drug therapy for rheumatoid arthritis. N Engl J Med 1994; 330:1368-1375.

6. Heidari B. Rheumatoid Arthritis: Early diagnosis and treatment outcomes. Caspian Journal of Internal Medicine 2011;2(1):161-170.

\footnotetext{
Authors Contribution:

BKM- Concept and design of study, Review of literature, data collection; PKK- Critical review of the study, data analysis; DPR- Statistical analysis and interpretation and preparation of manuscript

Work Attributed to:

Department of Pharmacology, PT JNM Medical College, Raipur (CG)

Orcid ID:

Dr. Basant Kumar Maheshwari: ittp://orcid.org/0000-0003-3829-8925

Dr. Prafulla Kumar Khodiar: (1) http://orcid.org/0000-0002-9254-9396

Dr. Debapriya Rath: (1) http://orcid.org/0000-0003-1908-2416

Sources of support: None, Conflict of Interest: None declared.
} 